\title{
RoboTalk \\ Prototyping a Humanoid Robot as a Speech-to-Sign Language Translator
}

\author{
Daniel Christian Homburg and Mirja Sophie Thieme, \\ Edith-Stein School, Darmstadt, Germany, E-Mail: robotalk@gmx.de \\ Johannes Völker and Ruth Maria Stock \\ Technische Universität Darmstadt, Germany, E-Mail: $\underline{\text { sekretariat@bwl.tu-darmstadt.de }}$
}

\begin{abstract}
Acknowledgements:
1) The authors thank the Förderverein für Marktorientierte Unternehmensführung, Invensity, Deutscher Sparkassenverlag, VorsprungAtWork, and Taunussparkasse for the financial support of the research. Furthermore, the authors thank Franz Bönsel from the Edith-Stein School for the great support of the research. Finally, the authors thank Felix Wendt from FiberThree for the great support with resources and advice during the printing process of the Robot.

2) The idea and the major part of this research owes to the two first authors (Daniel Homburg and Mirja Thieme). The two first authors conducted this research in the context of the program "Jugend forscht - Schüler experimentieren" at the Edith-Stein School, Darmstadt, Germany. The paper was written by the first author and refined and edited by the fourth author. The third author (Johannes Völker) supported the project with valuable advice about programming issues.
\end{abstract}

\begin{abstract}
Information science mostly focused on sign language recognition. The current study instead examines whether humanoid robots might be fruitful avatars for sign language translation. After a review of research into sign language technologies, a survey of 50 deaf participants regarding their preferences for potential reveals that humanoid robots represent a promising option. The authors also 3D-printed two arms of a humanoid robot, InMoov, with special joints for the index finger and thumb that would provide it with additional degrees of freedom to express sign language. They programmed the robotic arms with German sign language and integrated it with a voice recognition system. Thus this study provides insights into human-robot interactions in the context of sign language translation; it also contributes ideas for enhanced inclusion of deaf people into society.
\end{abstract}

\section{Introduction}

More than $5 \%$ of the world's population, or approximately 360 million people, are deaf or hearing impaired (328 million adults, 32 million children) [58]. In the United States, 28 million deaf and hearingimpaired people form the largest disability group [7].
In Europe, people with complete hearing loss make up approximately $0.05 \%$ of the population [44]. Both deaf and hearing-impaired people experience severe hearing loss, but 'The term 'deaf' is often used to refer to persons with severe hearing loss without the use of assistive devices. The term 'hearing impaired' is generally used to refer to persons with hearing loss up to 81 percent loss" [1, p. 108 ; for a further classification, see 57].

In many countries, sign language is the first language for people with hearing loss [32]. This natural language uses "movements of hands, body, face and head to produce an infinite number of varied sentences" [57]. However, it is not a universal language, such that different countries maintain their own national sign languages. For example, German sign language is a one-handed, fingerspelling language (see Figure 1). It features some similarities with French and other European sign languages [15]. The 80,000 deaf and 16,000,000 hard-hearing people in Germany [19] constitute about $20 \%$ of the population, among whom 140,000 experience at least $70 \%$ hearing impairment, such that it is difficult for them to communicate, especially with people unfamiliar with German sign language. In turn, "Everyday communication with the hearing population poses a major challenge to those with hearing loss. Although many deaf people lead successful and productive lives, 
overall, this communication barrier can have detrimental effects on many aspects of their lives" [7, p. 1]. In many cases, they rely on sign language interpreters in their daily lives. ${ }^{1}$

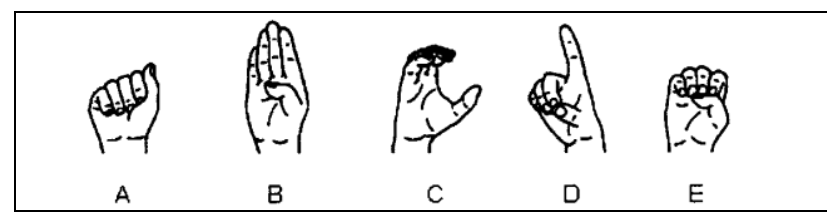

Figure 1: Samples for German sign language [57]

Such reliance is problematic for several reasons, including the lack of independence it implies and the limitations on people's integration into society. For example, even as deaf students increasingly have enrolled in universities, more than $80 \%$ of the hearingimpaired population worldwide is considered undereducated, due to a lack of support, [44] as well as educational difficulties stemming from an inability to follow lectures, low self-esteem, experienced isolation, and social barriers [10, 55]. Thus, "effective technological support is essential to enhance the learning environment of deaf and hearing-impaired learners" [7, p. 107]. Various technical applications have been developed [51, 54], but we propose going a step further to address the multiple needs of this population.

Specifically, we consider whether a humanoid robot can function as an avatar for sign language expression. Robots are "automatically controlled, reprogrammable, [and] multipurpose" [41, p. 402]; modern humanoid robots possess human-like physical traits (e.g., head, arms) but still look mechanical. These robots already help humans in various settings, whether by providing assistance to elderly and older people [16, 60], offering entertainment [24], supporting educational efforts [11], or providing health care services [8, 43]. Medical support robots in particular already provide rehabilitation tools [27], assist cognitively impaired people [33, 53], and motivate people to exercise or lose weight [22]. With a similar logic, we posit that humanoid robots may be able to translate and express sign languages. For example, a robotic sign language translator (RSLT) in school classes that include both hearing-impaired and nonhearing-impaired students could translate teachers' speech immediately to sign language, in support of the inclusion of all students

To develop a humanoid robot that facilitates communication by and with deaf and hearing-impaired people, we undertook the project "RoboTalk." It seeks

\footnotetext{
${ }^{1}$ The German statistics only includes deaf people. The European statistics includes hard hearing and deaf people.
}

to develop a humanoid robotic avatar that can function as a sign language translator. In developing this tool, we focus specifically on the needs of users and gather their insights to define the direction of our research, as well as which features the robot should possess. In particular, we established our first research question as:

1. How do potential users (i.e., deaf or hard-of-

hearing people) perceive the use of a robotic sign language translator (RSLT)?

Accordingly, we started with a survey of deaf and hearing-impaired potential users, to learn more about their likely acceptance and needs for such a new technology. An initial insight revealed that these potential users considered speech-to-sign language translation significantly more important than vice versa. Thus, we sought to build a prototype that could translate spoken language into sign language. Research on robots that can express themselves in sign language is scarce, particularly because most existing robots lack the manual dexterity required to perform the complicated finger gestures of sign language. Therefore, we also ask:

\section{How can the arms and hands of a robot be}

designed to allow the expression of complex

operations (i.e., letters, words) in sign language?

For this project, we used $3 \mathrm{D}$ printing to create the arms of a humanoid robot. As a foundation, we used a robot model called "InMoov" [28], for which individual components are widely available. However, the robot's existing thumb, index finger, and middle finger are not very flexible, so we sought to redevelop and print these three parts. To control the hands and arms at the same time, we attached them to a humansized doll, which we called Robert, and connected them via cables. Next, to teach the robot sign language, we considered which signs can be expressed with two arms and hands. That is, the third question asked,

3. Which signs in sign language can be expressed by two arms and hands?

In answering these questions, this article begins with a literature review of robotic and sign language research, which leads us to propose a three-stage model. We present the findings from a survey of 50 German deaf or hearing-impaired people in Section 4. Then in Section 5, we describe different elements of the system architecture and the general platform for the sign language robot Robert, followed by the user interaction process and some experimental tests of users' sign language recognition and robot acceptance (Section 6). We also outline some research implications and limitations. 


\section{Literature Review}

Extant studies on sign language essentially focus on three areas: A first group of studies examines aspects of sign language learning, teaching, and development in childhood stage $[18,34,39]$. These studies provide valuable insights on how sign language is created as first language in different life stages. It also helps us to program sign language for the robot. A second group of studies focuses on sign language recognition, reading, and interpretation [40, 45, 46, 48, 56]. A third research group investigates sign language expression through various technologies, such as screens and virtual avatars $[5,6,9,13,14,30,52]$. For our research, the third group is particularly important. Table 1 contains a summary of relevant literature. Most extant research describes techniques for either recognizing or expressing sign language. Several studies deal with the detection of American, Indian, or Chinese body language, using stereo cameras, gloves, or animated screens. Other studies also address ways to recognize different national sign languages (e.g., English, Chinese, Indian, Greek) [7, 17, 35, 38].

Table 1: Overview of key research on technology-based sign language devices

\begin{tabular}{|c|c|c|c|c|c|}
\hline Authors & $\begin{array}{c}\text { Sign } \\
\text { Language } \\
\text { Device }\end{array}$ & $\begin{array}{c}\text { Sign } \\
\text { Language } \\
\text { Mode }^{\mathrm{a})}\end{array}$ & $\begin{array}{c}\text { Coun- } \\
\text { try }\end{array}$ & $\begin{array}{c}\text { Me- } \\
\text { thod }^{\text {b) }}\end{array}$ & Key Findings \\
\hline $\begin{array}{l}\text { Barros et al. } \\
{[4]}\end{array}$ & $\begin{array}{l}\text { Camera of } \\
\text { NAO robot }\end{array}$ & $\mathrm{R}$ & USA & $E$ & $\begin{array}{l}\text { Recognition of hand postures recorded by a } \\
\text { robot camera in real-time, in a real-world } \\
\text { application scenario }\end{array}$ \\
\hline $\begin{array}{l}\text { Brashear, } \\
\text { Starner, \& } \\
\text { Lukowicz [7] }\end{array}$ & $\begin{array}{l}\text { Wearable } \\
\text { accelerometer } \\
\text { network }\end{array}$ & $\mathrm{R}$ & USA & $\bar{E}$ & $\begin{array}{l}\text { - Wearable accelerometer network } \\
\text { (computer, heads-up display, hat-mounted } \\
\text { camera) } \\
\text { - Rule-based grammar for sentence structure } \\
\text { - } 65.87 \% \text { recognition rate for accelerometer; } \\
90.48 \% \text { recognition rate for accelerometer } \\
\text { with vision }\end{array}$ \\
\hline $\begin{array}{l}\text { Efthimiou \& } \\
\text { Fortinea [12] }\end{array}$ & $\begin{array}{l}\text { Video of sign } \\
\text { language } \\
\text { corpus }\end{array}$ & $\mathrm{R}$ & Greece & $\mathrm{D}$ & $\begin{array}{l}\text { Sentence-level recognition (cf. sentence } \\
\text { boundaries) }\end{array}$ \\
\hline Gao et al. [17] & Glove & $\mathrm{R}$ & China & $\bar{E}$ & $\begin{array}{l}\text { - Self-organized feature maps for different } \\
\text { signers, with feature extractor for con- } \\
\text { tinuous hidden Markov models } \\
\text { - Word recognition rate of } 82.9 \% \text { with a } \\
\text { 5113-sign vocabulary }\end{array}$ \\
\hline $\begin{array}{l}\text { Karpouzis et } \\
\text { al. [21] }\end{array}$ & $\begin{array}{l}\text { Animated } \\
\text { screen }\end{array}$ & $\mathrm{E}$ & Greece & $\mathrm{D}$ & $\begin{array}{l}\text { - Written Greek text transformed into sign } \\
\text { language and animated on screen } \\
\text { - Syntactic parser decodes the structural } \\
\text { patterns of written Greek sign language and } \\
\text { matches them in equivalent patterns }\end{array}$ \\
\hline $\begin{array}{l}\text { Mehdi \& } \\
\text { Kahn [35] }\end{array}$ & Sensor gloves & $\mathrm{R}$ & USA & $\mathrm{C}$ & $\begin{array}{l}\text { Application of artificial neural networks to } \\
\text { recognize sensor values. }\end{array}$ \\
\hline $\begin{array}{l}\text { Kipp et al. } \\
\text { [23] }\end{array}$ & $\begin{array}{l}\text { Signing } \\
\text { avatars (virtual } \\
\text { characteristics) }\end{array}$ & $\mathrm{E}$ & $\begin{array}{c}\text { Germa } \\
\text { ny }\end{array}$ & $\mathrm{E}$ & $\begin{array}{l}\text { - Methods to assess signing avatar accep- } \\
\text { tability for deaf people (focus groups) } \\
\text { - Deaf people prefer non-interactive, simple } \\
\text { scenarios (e.g., information in train, } \\
\text { museum) }\end{array}$ \\
\hline $\begin{array}{l}\text { Kose \& Yorg- } \\
\text { annci [25] and } \\
\text { Kose et al. [26] }\end{array}$ & NAO H 25 & $\bar{E}$ & Turkey & $\mathrm{Ev}$ & $\begin{array}{l}\text { Sign language teaching robot for } 106 \\
\text { preschool children, using interaction games }\end{array}$ \\
\hline
\end{tabular}




\begin{tabular}{|c|c|c|c|c|c|}
\hline Authors & $\begin{array}{c}\text { Sign } \\
\text { Language } \\
\text { Device }\end{array}$ & $\begin{array}{c}\text { Sign } \\
\text { Language }^{\text {Mode }^{\mathrm{a}}}\end{array}$ & $\begin{array}{c}\text { Coun- } \\
\text { try }\end{array}$ & $\begin{array}{l}\text { Me- } \\
\text { thod }^{\text {b) }}\end{array}$ & Key Findings \\
\hline $\begin{array}{l}\text { Lee \& Xu } \\
{[29]}\end{array}$ & Cyberglove & $\mathrm{R}$ & USA & $\mathrm{D}$ & $\begin{array}{l}\text { - Online learning of new gestures } \\
\text { - Reliable recognition of } 14 \text { different gestures } \\
\text { - Application of hidden Markov models }\end{array}$ \\
\hline $\begin{array}{l}\text { Malima, } \\
\text { Özgür, \& } \\
\text { Çetin [31] }\end{array}$ & Real hands & $\mathrm{R}$ & Turkey & $\mathrm{D}$ & $\begin{array}{l}\text { Algorithm for automatic recognition of a } \\
\text { limited set of gestures from hand images }\end{array}$ \\
\hline $\begin{array}{l}\text { Mouri, } \\
\text { Kawasaki, \& } \\
\text { Umbayashi } \\
{[36]}\end{array}$ & $\begin{array}{l}\text { Anthropomor- } \\
\text { phic robot } \\
\text { (KH hand type } \\
\text { S) }\end{array}$ & $\mathrm{E}$ & Japan & $\bar{D}$ & $\begin{array}{l}\text { - Anthropomorphic robot hand } \\
\text { - Dexterous manipulation and displaying } \\
\text { hand shape } \\
\text { - Five fingers of robot are directed by a } \\
\text { bilateral controller }\end{array}$ \\
\hline $\begin{array}{l}\text { Nandy et al. } \\
{[38]}\end{array}$ & Robot & $\mathrm{R}$ & India & $\mathrm{E}$ & $\begin{array}{l}\text { - Real-time Indian sign language recognition } \\
\text { by humanoid robot } \\
\text { - Categorization of gestures with Euclidean } \\
\text { distance method }\end{array}$ \\
\hline $\begin{array}{l}\text { Starner \& } \\
\text { Pentland [49] }\end{array}$ & $\begin{array}{l}\text { Human hands } \\
\text { with and } \\
\text { without gloves }\end{array}$ & $\mathrm{R}$ & USA & E & $\begin{array}{l}\text { - System for American sign language } \\
\text { - Hands with colored gloves (accuracy 99\%), } \\
\text { hands without gloves (92\% accuracy) }\end{array}$ \\
\hline $\begin{array}{l}\text { Starner, } \\
\text { Weaver, \& } \\
\text { Pentland [50] }\end{array}$ & $\begin{array}{l}\text { Desk and } \\
\text { wearable } \\
\text { computer- } \\
\text { based videos }\end{array}$ & $\mathrm{R}$ & USA & $\mathrm{E}$ & $\begin{array}{l}\text { - Computer vision-based method of } \\
\text { recognizing sentence-level American sign } \\
\text { language from a } 40 \text { word lexicon } \\
\text { - Use of hidden Markov models } \\
\end{array}$ \\
\hline
\end{tabular}

a) The sign language modes are either $\mathrm{R}=$ recognition or $\mathrm{E}=$ expression. ${ }^{\mathrm{b}}$ The methods include $\mathrm{E}=$ experiment, $\mathrm{C}=$ conceptual article, $\mathrm{Ev}=$ Event, and $\mathrm{D}=$ hardware/software design.

One study used sensor gloves to recognize sign language and translate it into normal language [35]. Few works focus on speech-to-sign language translation though. Mouri and colleagues [36] have developed a robot hand that expresses Japanese sign language, and researchers have developed a robot body to express Greek sign language [21]. Some isolated studies also try to program a humanoid robot, such as NAO, using sign language [4], but this robot only has three fingers, which limits expressivity. Many studies rely on displaying pictures of hands making the signs on screens [20].

Such contributions indicate the possibility of programming at least some sign language capabilities for robots. We know of no studies that explicitly aim to establish complicated abbreviations of sign language by using human-like hands (and arms) with five fingers. Thus, the current research is the first to develop a robotic avatar that can translate speech to sign language.

\section{Three-Stage Research Process}

We depict the three research stages in Figure 2. First, we sought to identify important features for an RSLT, which directed our development and the design of the robotic arm. We also tested users' acceptance of Robert the RSLT, relative to a human translator. Second, for the construction and prototyping of arms, we developed a testable robotic arm. The major challenge in this stage was to create a robotic arm with fingers that were sufficiently flexible to express complex letters and words in sign language. We also started programming the sign language. Third, in an ongoing stage, we are conducting experiments to test participants' recognition of robotic signs and their acceptance of the RSLT. 


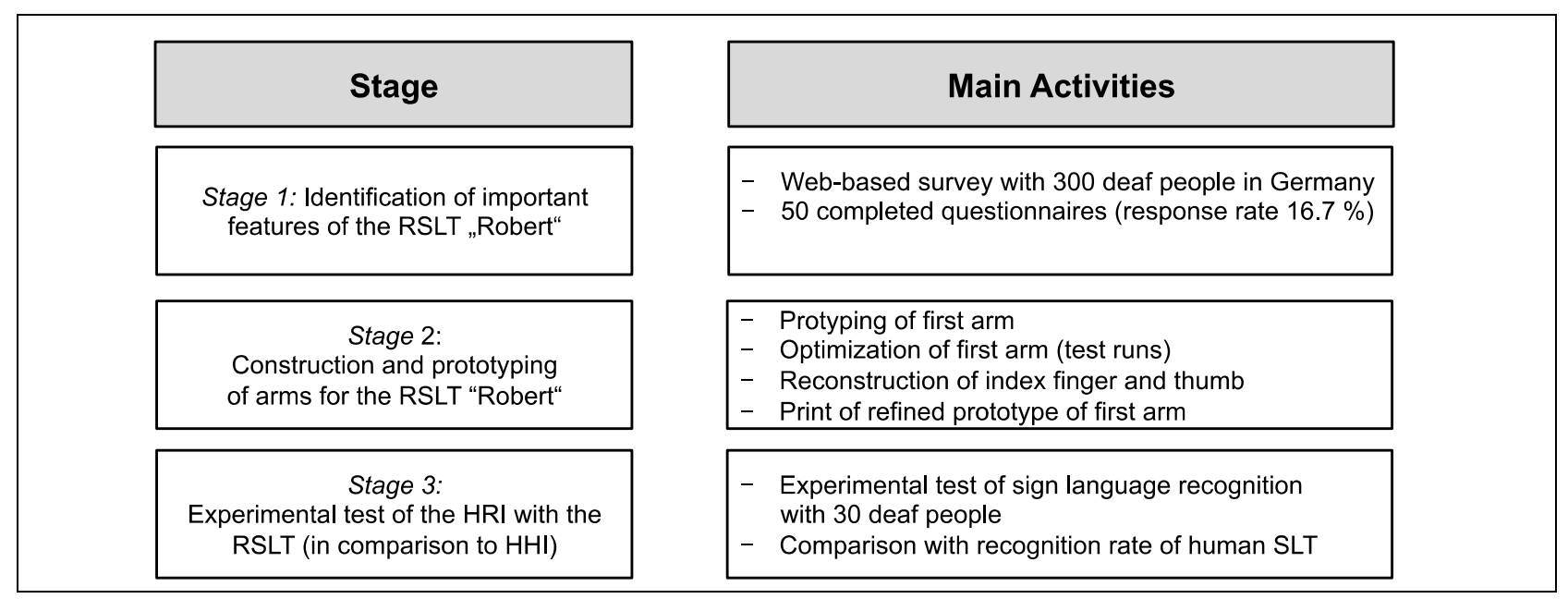

Figure 2: Three stages of the research project

\section{Survey with German Deaf and Hearing-Impaired People (Stage 1)}

\subsection{Sample}

We personally contacted 300 deaf or hearingimpaired people during community meetings and asked them to join the study, by distributing links to an online questionnaire (https://drive.google.com/file/d/1L9D-

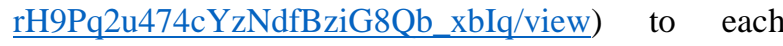
member. The study was identified as scientific research, de-signed to gain insights into deaf people's preferences for sign languages. The 61 returned questionnaires included 7 incomplete ones, for a $18.0 \%$ response rate; 54 questionnaires thus remain available for the analyses.

A test of nonresponse bias that compared early and late respondents [3] showed no significant differences in responses about potential disadvantages due to hearing impairment. The sample included $40.8 \%$ women. In terms of age, $10.4 \%$ were younger than 20 years, $28.1 \%$ between 21 and 24 years, $17.5 \%$ between 25 and 29 years, $11.3 \%$ between 30 and 39 years, $15.8 \%$ between 40 and 49 years, and $16.9 \%$ older than 50 years.

\subsection{Results}

This study seeks to specify in which areas of daily life deaf people feel excluded from society (Figure 3, Panel a). With these insights, we ensure that the RSLT that we develop can support inclusivity for deaf people in meaningful ways.

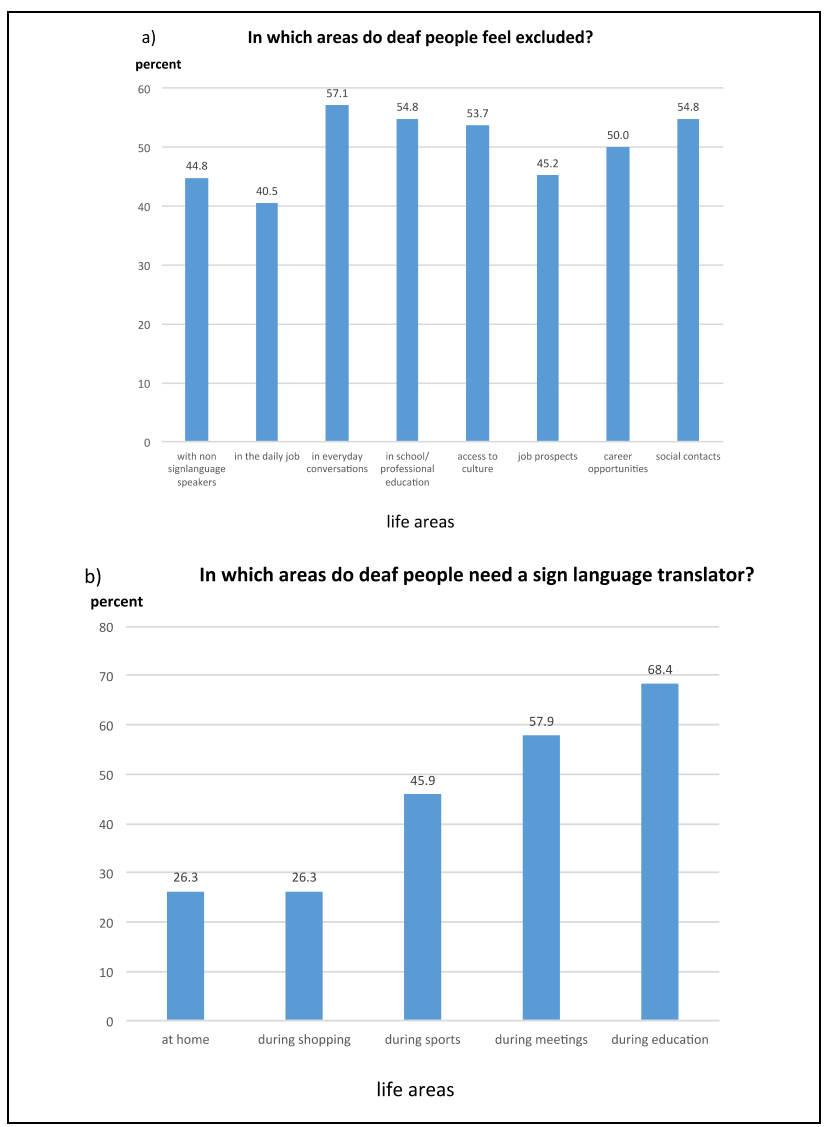

Figure 3: Relevant areas of discrimination and needs for sign language translator 
As Figure 3 indicates, deaf and hearing-impaired people feel excluded from various life areas, nearly all the time. This exclusion appears particularly prominent in private social settings and relationships, rather than in job-related areas. The survey respondents also indicate that their greatest need for a sign language translator arises during meetings with hearing people and for education (Panel b), because "most hearing people do not know sign language and know very little about Deafness in general. For example, most hearing people do not know how to communicate in spoken language with a Deaf or hard-of-hearing person who can speak and read lips (e.g. that they should turn their head or not to cover their mouth)" [58, p. 1].

In addition, we asked respondents to rate the importance of three possible capacities of a RSLT: (a) speech-to-sign language, (b) sign language-to-speech, or (c) both. Notably, $79 \%$ preferred both functions, but these respondents also considered speech-to-sign language translation tools as significantly more important than the other way around $(\mathrm{M}=4.09, \mathrm{SD}=$ .53 vs. $\mathrm{M}=2.98, \mathrm{SD}=.45 ; 7$-point scale). This finding is surprising; according to our literature review, extant research mostly has focused on sign language-tospeech capacities. Thus, we have determined that the RSLT we develop should be able to translate in both directions. However, considering its importance to potential users, we start by seeking to develop a speech-to-sign language feature.

We also uncover some divergent preferences regarding application areas for different sign language support modes. As we detail in Figure 4, about onethird of the respondents could not imagine being supported by a RSLT; in response to an open question, most cited their lack of experience as the reason for their reluctance to interact with a humanoid robot. Still, they acknowledge the potential of RSLTs at information desks (27.3\%), and some respondents think that everybody should have one $(17.4 \%)$. In particular, using RSLTs would align with the widely growing trend in which robots provide various services, including staffing information desks at airports, fairs, and hotels. In these areas, RSLT could provide valuable translation services for deaf guests.

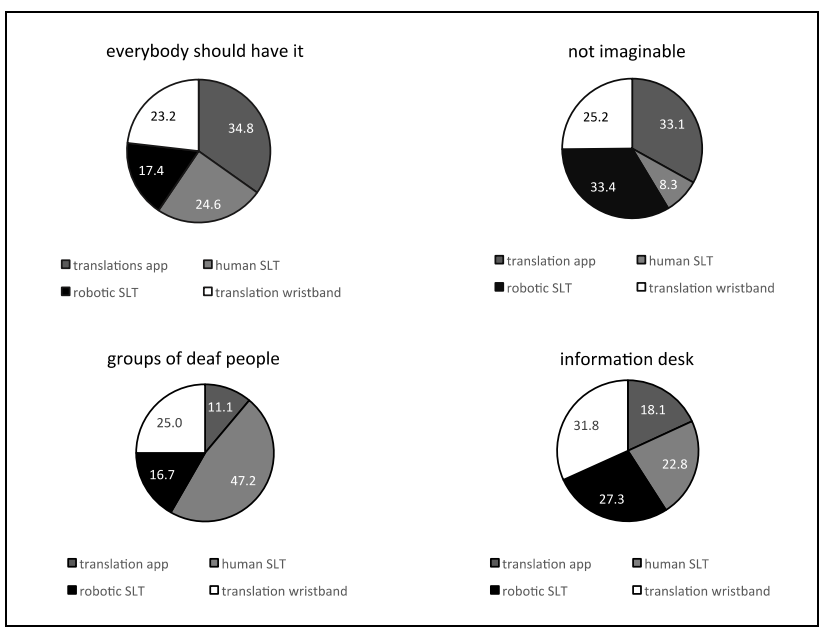

Figure 4: $\quad$ Areas of usage for a RSLT as compared to existing sign language translators

The respondents considered the robot as particularly important for information desks and for larger groups. From these findings, we conclude that a sign language robot may also be particularly accepted by groups of students at school or university.

The importance of robots at information desks is consistent with the trend that firms increasingly place humanoid robots at service encounters with customers because they provide a "richer" interaction than screens or self-service terminals [47]. During these interactions, humanoid robots are argued to be superior to a sign language translation screen, because these robots have been shown to express and transfer emotions to humans [59]. We argue that humanoid robots can enrich an interpersonal interaction and sign language translation by its human-like expressions.

\section{Construction and System Architecture for RSLT Robert (Stage 2)}

We printed a model of a robotic hand for "InMoov" that is freely available from the Internet [28]. Figure 5, Panel a depicts the exact measurements of the hand and shows the additional degrees of freedom of thumb and index finger. 
(a) Hand of RSTL „Robert“

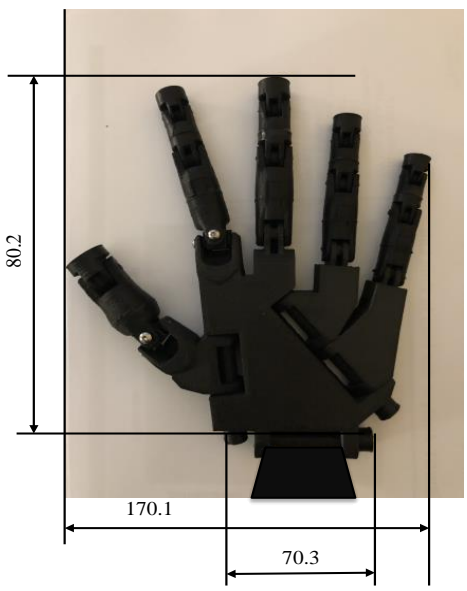

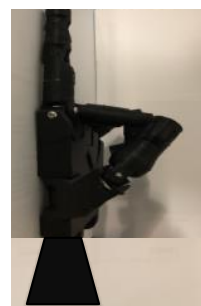

(b) "D"

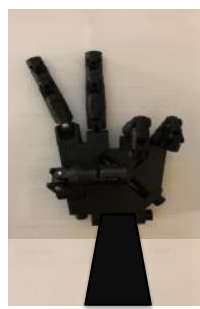

(d) "V"

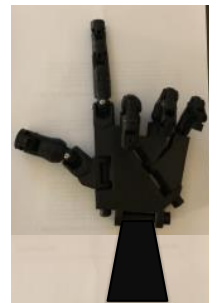

(c) " $\mathrm{L}$ "

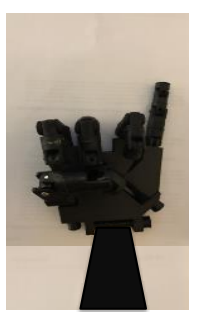

(e) "I"

Figure 5: Hand of the RSLT Robert and sample expressions of the German finger alphabet

The hand is driven by six motors. Each finger is run by a single motor, and the sixth motor directs the wrist. During the test of this prototype, we noticed that the thumb and index finger, which originally had just one degree of freedom, needed more leeway for many gestures. The original joint was too simple (Figure 5, Panel c), such that the pointer finger and thumb could only move one-dimensionally, making cross- movements impossible. For the first two fingers of the second hand, we had to develop new joints to allow the fingers to move in two directions.

Using two prototype robotic arms with more flexible fingers, we programmed the hand movements with Python. We started with the alphabet and numbers in sign language, then moved to words and sentences. Figure 6 depicts our RSLT architecture.

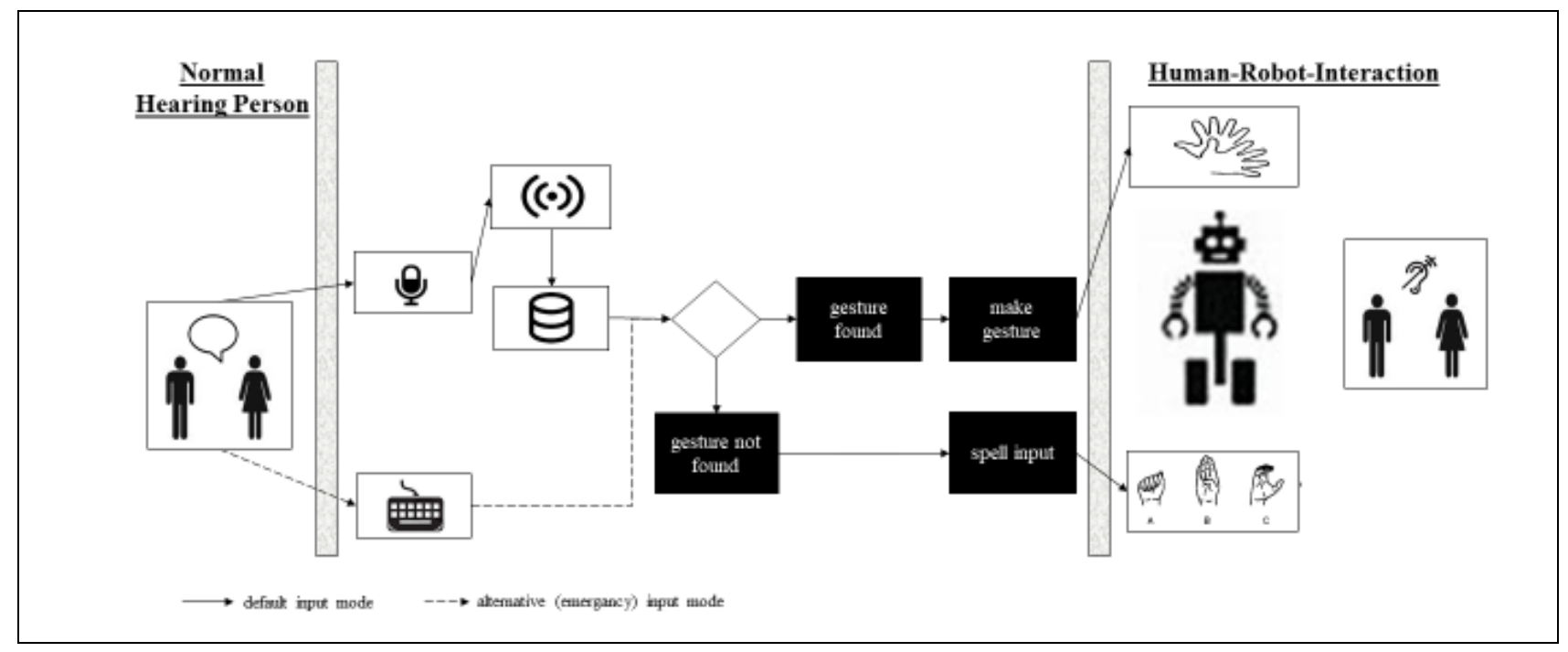

Figure 6: System architecture of the RSLT 
At the beginning of the process, a normal hearing user submits a voice message using a microphone (default input mode), which Robert translates into sign language. That is, upon a voice submission. We use Google speech recognition. The user's input gets transferred to a cloud database via WiFi. If WiFi is not available, the input can be provided by a user typing on a keyboard. Then the system compares the input with the data in the database. If a comparable word or term appears in the database, the robot expresses the preprogrammed sign language gesture. If no adequate sign output suggestion exists in the system, the robot spells each letter of the input. We connected a regular computer with a microcontroller. The micro controller directs the motors.

The robot is able to show every letter of the alphabet, numbers from one to 20, and words that can be expressed with two hands (and without further gestures by the head) $)^{2}$. If the robot is not able to translate a word, it will spell the word with single letters of the sign language alphabet. For example, it can translate the word "hello" and thus shows it with the sign that can be done with two hands. A word is not as easy to show as a letter or a number. Furthermore, the expression of single letters can vary in terms of their difficulty levels. For example, an " $r$ " is not as easy to express as an " $a$ ", because the " $r$ " needs to get the index finger and the middle finger crossed.

\section{Discussion}

\subsection{Research Implications}

People who experience hearing limitations face considerable challenges in their daily lives. The current research therefore attempts to enhance the inclusion of hearing-impaired and deaf people by developing a prototype for a robotic sign language translator (RSLT). We extend prior robotic research in several important directions. First, as our literature review shows, extant research largely focuses on sign language recognition, mostly in relation to visual recognition or deep learning. Our developed robotic prototype Robert is, to the best of our knowledge, the first system that can translate speech into sign language.

Second, this investigation contributes to research on assistive education robots. These robots mainly have been applied to teach psychologically disabled people [42] or supervise users and ensure their acquisition of technical skills [2, 37]. We propose an extension, such that language robots might teach sign language, as well as assist teachers in classrooms by translating their speech immediately, to increase the inclusion of hearingimpaired students in conventional school classes.

\subsection{Limitations and Areas for Further Research}

This research project is ongoing, seeking continuous improvements to the Robert prototype. Currently, the focus is on speech-to-sign translation; we hope that further research identifies means to integrate existing sign language recognition technologies to achieve comprehensive capabilities for both translation directions. This research has several limitations that may offer interesting areas for future research: First, this research focuses on speech-to-sign translation without offering a vice versa option. Future research could develop an integrated humanoid robot, being able to provide both, speech-to-sign and sign-to-speech. Second, with today's speech recognition, the robot cannot understand everything one tells him. In classes with school or college students, it can sometimes be very loud and the robot could have hearing difficulties. Third, so far, the robot is only able to show rather simple signs. Fourth, this study surveyed 50 sign language speaking people in Germany. Future research could study potential cultural differences based on a larger sample.

We recently tested the prototype in a laboratory setting, demonstrating that the current iteration of Robert can express the entire German sign language alphabet and a set of about 50 words. We will soon conduct tests of the extent to which hearingimpaired or deaf people can recognize the sign language that Robert expresses, in an experimental study. This experiment will indicate if our efforts to develop specific joints and fingers that offer sufficiently flexible hand and finger movements to express sign language have been sufficient. We also plan to compare human-robot interactions with human-human interactions, by determining people's recognition of sign language expressed by the robot compared with that of sign language expressed by a human sign language translator.

\footnotetext{
${ }^{2}$ Several words of the sign language require head gestures and mimical expressions.
} 


\section{References}

[1] Abuzinadah, N. E., Malibari, A. A., and Krause, P. (2017). Towards empowering hearing impaired students' skills in computing and technology. International Journal of Advanced Computer Science and Application, 8 (1), 107-118.

[2] Akrour, R., Schoenauer, M., \& Sebag, M. (2013, September). Interactive robot education. ECML/ PKDD Workshop on Reinforcement Learning with Generalized Feedback: Beyond Numeric Rewards.

[3] Armstrong, J. S., \& Overton, T. S. (1977). Estimating nonresponse bias in mail surveys. Journal of Marketing Research, 14(3), 396402.

[4] Barros, P., Magg, S., Weber, C., \& Wermter, S. (2014). A multichannel convolutional neural network for hand posture recognition. International Conference on Artificial Neural Networks, September (pp. 403-410). Springer, Cham.

[5] Bellugi, U., \& Fischer, S. (1972). A comparison of sign language and spoken language, Cognition, 1(23), 173-200.

[6] Bowden, R., Windridge, D., Kadir, T., Zisserman, A., \& Brady, M. (2004, May). A linguistic feature vector for the visual interpretation of sign language, European Conference on Computer Vision (pp. 390-401). Springer, Berlin, Heidelberg.

[7] Brashear, H., Starner, T., Lukowicz, P., \& Junker, H. (2003). Using multiple sensors for mobile sign language recognition. Georgia Institute of Technology.

[8] Broadbent, E., MacDonald, B., Jago, L., Juergens, M., \& Mazharullah, O. (2007). Human reactions to good and bad robots. Proceedings of the 2007 IEEE/RSJ Inter-national Conference on Intelligent Robots and Systems, San Diego, CA, USA, Oct 29 Nov 2.

[9] Chamberlain, C., \& Mayberry, R. I. (2008). American Sign Language syntactic and narrative com-prehension in skilled and less skilled readers: Bilingual and bimodal evidence for the linguistic basis of reading, Applied Psycholinguistics, 29(3), 367-388.

[10] Course, S. T. (2006). ICTs in education for people with special needs. In United Nations Educational, Scientific and Cultural Organisation. IITE Training Materials, Moscow.

[11] De Graaf, M. \& Ben Allouch, S. (2013). Exploring influencing variables for the acceptance of social robots. Robotics and Autonomous Systems, 61(12) 1476-1486.

[12] Efthimiou, E. \& Fotinea, S. E. (2007). GSLC: creation and annotation of a Greek sign language corpus for HCI. International Conference on Universal Access in Human-Computer Interaction, July (pp. 657-666). Springer, Berlin, Heidelberg.

[13] Elliott, R., Glauert, J. R., Kennaway, J. R., Marshall, I., \& Safar, E. (2008). Linguistic modelling and language-processing technologies for Avatar-based sign language presentation, Universal Access in the Information Society, 6(4), 375-391.

[14] Emmorey, K., Klima, E., \& Hickok, G. (1998), Mental rotation within linguistic and non-linguistic domains in users of American sign language, Cognition, 68(3), 221-246.

[15] Ethnologue (2018). German sign language. Ethnologue - Languages of the World, https://ethnologue.com/ language/gsg (research date: $03 / 30 / 2018$ ).
[16] Forlizzi, J. \& DiSalvo, C. (2006, March). Service robots in the domestic environment: a study of the Roomba vacuum in the home. In Proceedings of the 1st ACM SIGCHI/SIGART conference on Humanrobot inter-action (pp. 258-265). ACM.

[17] Gao, W., Fang, G., Zhao, D., \& Chen, Y. (2004). A Chinese sign language recognition system based on SOFM/SRN/HMM. Pattern Recognition, 37(12), 2389-2402.

[18] Gardner, R. A., \& Gardner, B. T. (1969). Teaching sign language to a chimpanzee, Science, 165(3894), 664-672

[19] German Deaf Association (2014).

[20] Habili, N., Lim, C. C., \& Moini, A. (2004). Segmentation of the face and hands in sign language video sequences using color and motion cues. IEEE Transactions on Circuits and Systems for Video Technology, 14(8), 1086-1097.

[21] Karpouzis, K., Caridakis, G., Fotinea, S. E., \& Efthimiou, E. (2007). Educational resources and implementation of a Greek sign language synthesis architecture. Computers \& Education, 49(1), 54-74.

[22] Kidd, C. D. \& Breazeal C. (2006). Sociable robot systems for weight maintenance. In: Proceedings of the 3rd IEEE Consumer Communications and Networking Conference, Las Vegas, Nevada, 253257.

[23] Kipp, M., Heloir, A., \& Nguyen, Q. (2011, September). Sign language avatars: Animation and comprehen-sibility. International Workshop on Intelligent Virtual Agents (pp. 113-126). Springer, Berlin, Heidelberg.

[24] Kirby, R., Forlizzi, J., \& Simmons, R. (2010). Affective social robot. Robotics and Autonomous Systems, 58, 322-332.

[25] Kose, H. \& Yorganci, R. (2011, October). Tale of a robot: humanoid robot assisted sign language tutoring. 11th IEEE-RAS International Conference on Humanoid Robots (Humanoids), (pp. 105-111).

[26] Kose, H., Yorganci, R., Algan, E. H., \& Syrdal, D. S. (2012). Evaluation of the robot assisted sign language tutoring using video-based studies. International Journal of Social Robotics, 4(3), 273283.

[27] Krebs, H. I., Palazzolo, J. J., Dipietro, L., Ferraro, M., Krol, J., Rannekleiv, K., Volpe, B. T., \& Hogan, N. (2003). Rehabilitation robotics: Performance-based pro-gressive robot-assisted therapy. Autonomous Robots, 15, 7-20.

[28] Langevin, G. (2017). InMoov. http://inmoov.fr [research date: 09/11/2017].

[29] Lee, C., \& Xu, Y. (1996, April). Online, interactive learning of gestures for human/ robot interfaces. In International Conference on Robotics and Automation, IEEE (Vol. 4, pp. 2982-2987).

[30] Liddell, S. K., \& Johnson, R. E. (1989), American sign language: The phonological base, Sign Language Studies, 64(1), 195-277.

[31] Malima, A. K., Özgür, E., \& Çetin, M. (2006). A fast algorithm for vision-based hand gesture recognition for robot control.

[32] Markellou, P., Rigou, M., Sirmakessis, S., \& Tsakalidis, A. (2000). A web adaptive educational system for people with hearing difficulties. Education and Information Technologies, 5 (3), 189-200.

[33] Matarić, M. J., Eriksson, J., Feil-Seifer, D. J., \& Winstein, C. J. (2007). Socially assistive robotics for post-stroke rehabilitation. Journal of Neuroengineering Rehabilitation, 4, 5. Page 1714 
[34] Mayberry, R. I. (1993). First-language acquisition after childhood differs from second-language acquisition: The case of American Sign Language. Journal of Speech, Language, and Hearing Research, 36(6), 1258-1270.

[35] Mehdi, S. A. \& Khan, Y. N. (2002). Sign language recognition using sensor gloves. Proceedings of the 9th International Conference on Neural Information Processing, 5 (November), pp. 22042206).

[36] Mouri, T., Kawasaki, H., \& Umebayashi, K. (2005). Developments of new anthropomorphic robot hand and its master slave system. International Conference on Intelligent Robots and Systems, IEEE/RSJ (pp. 3225-3230).

[37] Mubin, O., Stevens, C. J., Shahid, S., Al Mahmud, A., \& Dong, J. J. (2013). A review of the applicability of robots in education. Journal of Technology in Education and Learning, 1(209-15), 13.

[38] Nandy, A., Mondal, S., Prasad, J. S., Chakraborty, P., \& Nandi, G. C. (2010). Recognizing \& interpreting Indian sign language gesture for human robot interaction. International Conference on Computer and Communi-cation Technology, September, (pp. 712-717).

[39] Newport, E. L. (1988). Constraints on learning and their role in language acquisition: Studies of the acquisition of American Sign Language. language Sciences, 10(1), 147-172.

[40] Padden, C., \& Ramsey, C. (2000). American Sign Language and reading ability in deaf children. Language Acquisition by Eye, 1, 65-89.

[41] Piltan, F., Haghighi, S. T., Sulaiman, N., Nazari, I., \& Siamak, S. (2011). Artificial control of PUMA robot manipulator: A review of fuzzy inference engine and application to classical controller. International Journal of Robotics and Automation, 2(5), 401-425.

[42] Robins, B., Dautenhahn, K., Te Boekhorst, R., \& Billard, A. (2005). Robotic assistants in therapy and education of children with autism: can a small humanoid robot help encourage social interaction skills? Universal Access in the Information Society, 4(2), 105-120.

[43] Roy, N., Baltus, G., Fox, D., Gemperle, F., Goetz, J., Hirsch, T., \& Thrun, S. (2000). Towards personal service robots for the elderly. Workshop on Interactive Robots and Entertainment, 25, 184.

[44] Sandhu, J. S. \& Wood, T. (1990). Demography and market sector analysis of people with special needs in thirteen European countries: A report on telecommunication usability issues, RACE R1088 $T U D O R$, Special Needs Research Unit, Newcastle Polytechnic, Newcastle upon Tyne, UK.

[45] Senghas, A., \& Coppola, M. (2001). Children creating language: How Nicaraguan Sign Language acquired a spatial grammar. Psychological Science, 12(4), 323-328.

[46] Senghas, A., Kita, S., \& Özyürek, A. (2004). Children creating core properties of language: Evidence from an emerging sign language in Nicaragua. Science, 305(5691), 1779-1782.

[47] Silva, G., \& DeSocio, T. J. (2016). Meet Wally. The room service robot of the Residence Inn Marriott at LAX. Posted: February 17, 2016. http://www.fox-la.com/news/local-news/meetwally-the-room-service-robot-of-the-residence-innmarriott-at-lax [Research date: 4/11/2016].

[48] Singleton, J. L., \& Newport, E. L. (2004). When learners surpass their models: The acquisition of
American Sign Language from inconsistent input. Cognitive Psycho-logy, 49(4), 370-407.

[49] Starner, T. \& Pentland, A. (1997). Real-time American sign language recognition from video using hidden Markov models. Motion-Based Recognition (pp. 227-243). Springer, Dordrecht.

[50] Starner, T., Weaver, J., \& Pentland, A. (1998). Real-time American sign language recognition using desk and wearable computer based video. IEEE Transactions on Pattern Analysis and Machine Intelligence, 20(12), 1371-1375.

[51] Stephanidis, C., Savidis, A., \& Akoymianakis, D. (1995). Tools for user interfaces for all. In Proceedings of the 2nd TIDE Congress, Paris, France, 26-28 April, IOS Press, Amsterdam, 167170.

[52] Stokoe Jr, W. C. (2005). Sign language structure: An outline of the visual communication systems of the American deaf, Journal of Deaf Studies and Deaf Education, 10(1), 3-37.

[53] Tejima, N. (2001). Rehabilitation robotics: A review. Advanced Robotics, 14(7), 551-564.

[54] Vanderheiden, G. G. (1994). Application software design guidelines: Increasing the accessibility of appli-cation software to people with disabilities and older users. Trace R\&D Center, Dept. of Industrial Engineering University of WisconsinMadison at http://trace.wisc.edu/docs/software guidelines/software html.

[55] Van Gent, T., Goedhart, A. W., Knoors, H., \& Treffers, P. D. A. (2012). Self-concept and ego development in deaf adolescents: a comparative study. Journal of Deaf Studies and Deaf Education, 17(3), 333-351.

[56] Vogler, C., \& Metaxas, D. (2001). A framework for recognizing the simultaneous aspects of American sign language. Computer Vision and Image Understanding, 81(3), 358-384.

[57] Wareham, T., Clark, G., and Laugesen, C. (2001). Pro-viding learning support for d/deaf and hearing-impaired students undertaking fieldwork and related activities. Cheltenham, UK: Geography Discipline Network.

[58] Who.int. WHO (2015). Deafness and hearing loss. Available from http://www.who.int/mediacentre/ fact-sheets/ fs300/en/[research date: 05/06/2018].

[59] Xu, J., Broekens, J., Hindriks, K., \& Neerincx, M.A. (2014). Robot mood is contagious: Effects of robot body language in the imitation game. In Proceedings of the 2014 International Conference on Autonomous Agents and Multi-Agent Systems, 973-980.

[60] You, B. J., Hwangbo, M., Lee, S.O., Oh, S.R., Do Kwon, Y., \& Lim, S. (2003). Development of a home service robot 'ISSAC'. International Conference on Intelligent Robots and Systems IROS, 3, 2630-2635. 